Indonesian Journal of Physics

Vol 19 No. 4, October 2008

\title{
Evaluation of Pb-Bi-Water Direct Contact Boiling Flow in a Vertical Circular Channel using Drift-Flux Model
}

\author{
Novitrian $^{1)}$ and Minoru Takahashi ${ }^{2)}$ \\ 1) Nuclear Physics and Biophysics Research Division, \\ Institut Teknologi Bandung, \\ Jl. Ganesha No. 10 Bandung 40132, INDONESIA \\ ${ }^{2)}$ Research Laboratory for Nuclear Reactors, \\ Tokyo Institute of Technology, Tokyo 152-8550, JAPAN \\ e-mail: novit@fi.itb.ac.id
}

\begin{abstract}
The characteristics of $\mathrm{Pb}$-Bi-water boiling two-phase flow were investigated in a vertical circular channel. Water was injected into $\mathrm{Pb}$-Bi to circulate $\mathrm{Pb}-\mathrm{Bi}$ in a loop with an effect of steam lift pump. $\mathrm{Pb}$-Bi flow rates were measured and analytically estimated using balance condition between buoyancy force and pressure losses. The drift-flux model was used to determine void fraction with assumption that bubble sizes were dependent on the fluid surface tension and density ratio of $\mathrm{Pb}-\mathrm{Bi}$ to steam and water mixture. The result of analysis shows that the deviation from the experimental data was less than $20 \%$.
\end{abstract}

Keywords: Lead-bismuth, Direct contact, Steam lift pump, Two-phase flow, Drift-flux model

\section{Introduction}

Lead-bismuth $(\mathrm{Pb}-\mathrm{Bi})$ has been considered as a coolant candidate of fast reactors. The advantages of $\mathrm{Pb}-\mathrm{Bi}$ arise from the possibility of developing passively safe reactors with long lifetimes core, combined with low capital and operating cost. The reactor with a long-life core may be also useful for remote region islands. Smaller reactors are more suitable for transportation to un-industrialized area after being fabricated and assembled in factories. $\mathrm{Pb}-\mathrm{Bi}$ cooled Direct Contact Boiling Water Fast Reactor (PBWFR) has been proposed ${ }^{1-3}$ ). This reactor uses the steam lift pump concept based on the bubbling of water into $\mathrm{Pb}-\mathrm{Bi}$ coolant flow to enhance $\mathrm{Pb}-\mathrm{Bi}$ circulation flow.

Two-phase flow behaviors of steam-water and $\mathrm{Pb}-\mathrm{Bi}$ have been studied experimentally using $\mathrm{Pb}-\mathrm{Bi}-$ water direct contact boiling two-phase flow loop. In the previous work, experimental data of changes of temperatures and $\mathrm{Pb}-\mathrm{Bi}$ flow rate by the water injection into the $\mathrm{Pb}-\mathrm{Bi}$ flow has been reported ${ }^{4,5)}$. The two-phase flow characteristic in the channel was determined by the force balance between the buoyancy of two phase flow and the total pressure drop in the $\mathrm{Pb}-\mathrm{Bi}$ circulation loop ${ }^{5,6}$ including the two-phase flow pressure drop in the chimney.

In general, without the detail two-phase flow information needed to develop a flow regime map and the associated interfacial relation, the drift-flux models have often been used in the thermal-hydraulic analysis of nuclear and other systems. Appropriate correlations for the drift velocity and the drag coefficient between nitrogen gas and $\mathrm{Pb}-\mathrm{Bi}$ phase were based on the drift flux correlation of measured pool void fraction ${ }^{7)}$. And another correlation for drift-flux model between nitrogen gas and liquid metal for measured loop-type experiment void fraction ${ }^{8)}$.
In the previous analytical work $^{9)}$, nondimensional drift-flux model was used, where the gas and fluid superficial velocities depended on the fluid surface tension, and only the density ratio between phases was used for the drift velocity between phases and the distribution parameter.

The purpose of the present study is to investigate two-phase flow characteristics of $\mathrm{Pb}-\mathrm{Bi}$ steam-water boiling flow in the channel using the onedimensional drift-flux model, where the gas and fluid superficial velocities did not depend on the fluid surface tension, and both of the fluid surface tension and the density ratio between phases were considered for the drift velocity between phases, assuming the distribution parameter to be constant.

\section{Experimental Apparatus}

A schematic diagram of the $\mathrm{Pb}$-Bi-water direct contact boiling two-phase flow loop is shown in Figure 1. It consists of a $\mathrm{Pb}-\mathrm{Bi}$ flow loop and a watersteam loop. The $\mathrm{Pb}-\mathrm{Bi}$ loop consists of the heater pin bundle with four electrical heater pins, the chimney, an upper tank with the separator and dryer, the cooler, an electromagnetic flow meter, and a flow resistance (Figure 2). The water-steam loop consists of the cooler, the pre-heater, the chimney, the upper tank, the condenser and the buffer tank. Sub-cooled water was injected into the $\mathrm{Pb}-\mathrm{Bi}$ flow in the chimney. Boiling occurs in the chimney and serves as a steam lift pump for $\mathrm{Pb}-\mathrm{Bi}$ circulation flow. The steam goes to turbines after passing through the separator and dryer. 


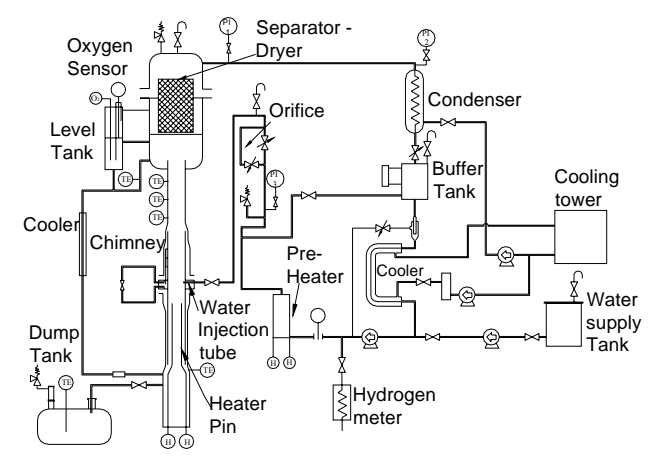

Figure 1. Flow diagram of $\mathrm{Pb}$-Bi-water direct contact boiling two-phase flow apparatus

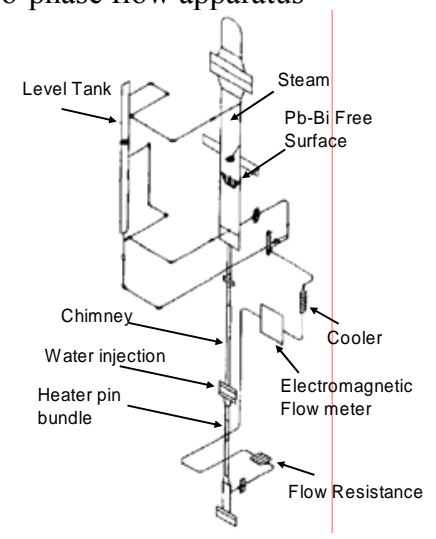

Figure 2. Schematic of $\mathrm{Pb}-\mathrm{Bi}$ flow loop in test apparatus

$\mathrm{Pb}-\mathrm{Bi}$ flow rates obtained from analytical model are compared with existing experimental data taken under various experimental conditions such as pressure of $0.01-7 \mathrm{MPa}, \mathrm{Pb}-\mathrm{Bi}$ inlet temperature of $278-414^{\circ} \mathrm{C}$ and injected water temperature of $198-$ $228^{\circ} \mathrm{C}$.

Figure 3 shows a schematic of the test section, i. e., the pin bundle, the chimney and the upper tank. Detailed specifications of the test section are listed in Table 1. Controlled parameters and the result of the operation are present in Table 2.

Water injection mass flow rate $G_{w}$ was measured with orifice flow meters and the $\mathrm{Pb}-\mathrm{Bi}$ mass flow rate $G_{L}$ was measured with the electromagnetic flow meter.

Table 1. Specifications of test section

\begin{tabular}{|l|l|}
\hline Length of the test section & $7,000 \mathrm{~mm}$ \\
\hline $\begin{array}{l}\text { Chimney } \\
\text { Inner diameter / Length }\end{array}$ & $29.9 \mathrm{~mm} / 2,367 \mathrm{~mm}$ \\
\hline $\begin{array}{l}\text { Upper tank containing separator } \\
\text { Inner diameter / Length }\end{array}$ & $254.4 \mathrm{~mm} / 3,150 \mathrm{~mm}$ \\
\hline $\begin{array}{l}\text { Heater pin bundle } \\
\text { Length }\end{array}$ & $1,720 \mathrm{~mm}$ \\
\hline Heater pin & 4 \\
Number & $12 \mathrm{~mm} / 1,650 \mathrm{~mm}$ \\
Outer diameter / Length & $15.9 \mathrm{~mm}$ \\
Pitch of rod arrangement & $1,000 \mathrm{~mm} / 33.3 \mathrm{~kW}$ \\
Heated length / Power & \\
\hline
\end{tabular}

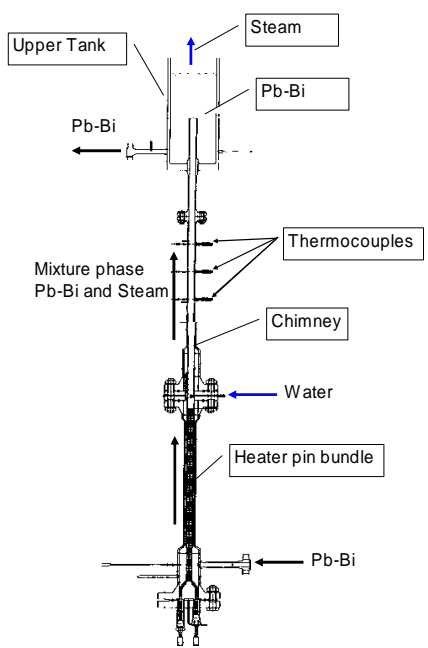

Figure 3. Schematic of test section

Table 2. Controlled parameters and result of operation

\begin{tabular}{|c|c|c|}
\hline Parameter & $\begin{array}{c}\text { Experimental } \\
\text { Condition }\end{array}$ & $\begin{array}{c}\text { Rated } \\
\text { Condition }\end{array}$ \\
\hline Heater Pin $\quad$ Power $(\mathrm{kW})$ & $5-106$ & 133 \\
\hline $\begin{array}{ll} & \text { Pb-Bi Temp. At Oulet } \\
\left({ }^{\circ} \mathrm{C}\right) & \end{array}$ & $308-469$ & 460 \\
\hline Injected water Flow rate $(\mathrm{kg} / \mathrm{h})$ & $5.8-245$ & 256 \\
\hline Temperature $\left({ }^{\circ} \mathrm{C}\right)$ & $198-228$ & 220 \\
\hline \multirow[t]{2}{*}{ Steam pressure $(\mathrm{MPa})$} & $0.1-7$ & 7 \\
\hline & Result & $\begin{array}{c}\text { Rated } \\
\text { Condition }\end{array}$ \\
\hline $\begin{array}{l}\text { Pb-Bi temp. at inlet of heater pin } \\
\text { bundle }\left({ }^{\circ} \mathrm{C}\right)\end{array}$ & $278-414$ & 310 \\
\hline $\mathrm{Pb}-\mathrm{Bi}$ flow rate $(\mathrm{L} / \mathrm{min})$ & $56-61$ & 36.5 \\
\hline Temperature in chimney $\left({ }^{\circ} \mathrm{C}\right)$ & $303-316$ & - \\
\hline
\end{tabular}

\section{Analysis}

\subsection{System and assumption}

Figure 4 shows a schematic diagram of $\mathrm{Pb}-\mathrm{Bi}$ water direct contact flow loop. The $\mathrm{Pb}-\mathrm{Bi}$ flows through the heater pin, the chimney, the upper tank, the cooler, the downward flow pipe and the electromagnetic flow meter. Sub-cooled water was injected into $\mathrm{Pb}-\mathrm{Bi}$ above the heater pin bundle and boiling occurred. $\mathrm{Pb}-\mathrm{Bi}$ flow rates were calculated analytically using balance condition between the buoyancy force and frictional pressure drops during the flow. The drift-flux model was used in calculating the buoyancy force in the chimney. The flowchart of the calculation is shown in Figure 5. The Pb-Bi flow is analyzed assuming one dimensional flow. In analysis, it was assumed that the bubble sizes were dependent on the fluid surface tension. 


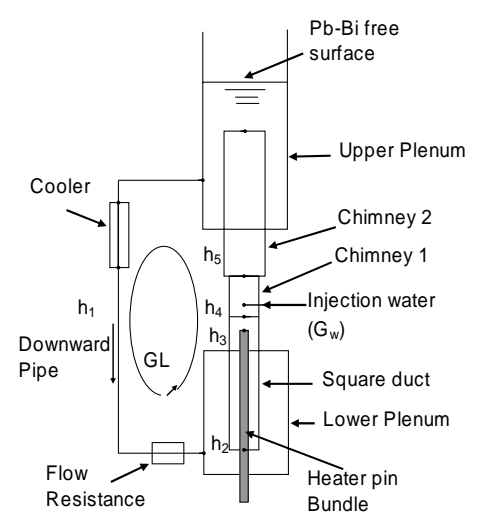

Figure 4. One dimensional flow model for $\mathrm{Pb}-\mathrm{Bi}$

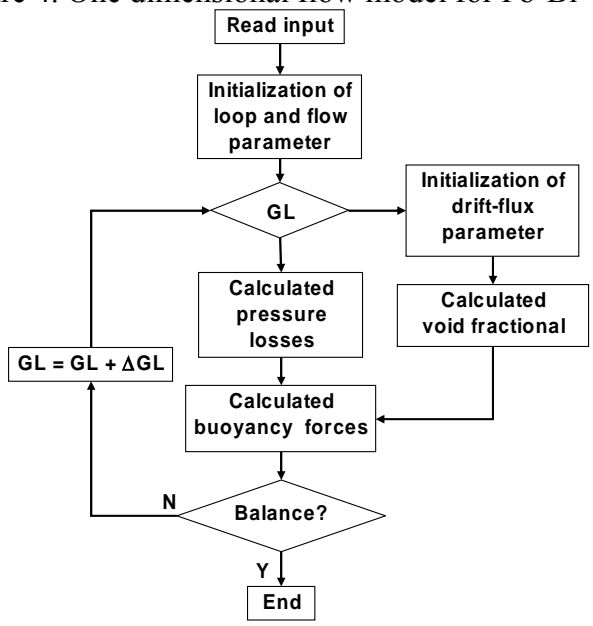

Figure 5. One dimensional calculation model for $\mathrm{Pb}$ $\mathrm{Bi}$

\subsection{Buoyancy force and pressure drop}

The buoyancy force of $\mathrm{Pb}-\mathrm{Bi}$ circulation by steam lift pump effect is given by

$$
\Delta P=\rho_{d c} h_{1} g-\left[\rho_{d c} h_{2}+\rho_{3} h_{3}+\rho_{4} h_{4}+\rho_{c}(1-\alpha) h_{5}\right] g,(1)
$$

where $\mathrm{h}$ denotes the channel height in each section, $\rho$ is $\mathrm{Pb}-\mathrm{Bi}$ density estimated from measured $\mathrm{Pb}-\mathrm{Bi}$ temperature, and suffices 1-5 indicate the channel locations of the downward flow channel, an inlet of the heater pin bundle, an exit of heater pin bundle, an inlet of an injection region and an inlet of the chimney, respectively, and $\alpha$ is the void fraction.

Frictional pressure drop of the $\mathrm{Pb}-\mathrm{Bi}$ - steam two-phase flow in the chimney is given by

$$
\Delta P_{T P}=\left(\phi_{L 0}\right)^{2} \Delta P_{L 0},
$$

where the pressure drop of $\mathrm{Pb}$-Bi single-phase flow and the velocity are given by

$$
\begin{aligned}
& \Delta P_{L 0}=\left[\zeta+\lambda\left(L / D_{e}\right)\right](\rho / 2) \cdot V_{p}^{2}, \\
& V_{p}=\left(G_{p}+G_{f}\right) /(\rho A) .
\end{aligned}
$$

where $\zeta$ is form loss coefficient, $\lambda$ is friction loss coefficient, $L$ is length of heater pin, $D_{e}$ is hydraulic diameter, $V_{p}$ is $\mathrm{Pb}$-Bi superficial velocity, $G$ is mass flow rate, and $A$ is total cross sectional area.

The two-phase multiplication factor is expressed by ${ }^{5)}$

$$
\left(\phi_{L O}\right)^{2}=\left[1+x\left(\rho_{p} / \rho_{w}-1\right)\right]\left[1+x\left(\mu_{p} / \mu_{w}-1\right)\right]^{-0.25},(5)
$$

where $x$ is the steam quality in a steam and $\mathrm{Pb}-\mathrm{Bi}$ mixture and is defined as $x=G_{f} /\left(G_{p}+G_{f}\right), \rho_{w}$ is the average density of the steam and water mixture and is defined as $\rho_{w}=\left[x_{w} / \rho_{g}+\left(1-x_{w}\right) / \rho_{f}\right]^{-1}, \rho_{c}$ is the average fluid density in the chimney and is defined as $\rho_{\mathrm{c}}=\alpha \rho_{w}+(1-\alpha) \rho_{p}$, and $\mu$ is dynamic viscosity, and $\mathrm{X}_{\mathrm{w}}$ is steam quality

Frictional pressure drop of bare bundle is expressed by

$$
\Delta P_{b}=(\rho / 2) . f \cdot\left(L / D_{e}\right)\left(V_{b}\right)^{2} .
$$

where $f$ is friction loss coefficient, $V_{b}$ is superficial velocity in bundle.

The flow is classified into the laminar flow in $R e \leq R e_{L}$, the transition flow in $R e_{L} \leq R e \leq R e_{T}$ and the turbulent flow in $R e \geq R e_{T}$, where

$$
\begin{aligned}
& R e_{L}=300 \times 10^{1.7(\mathrm{P} / \mathrm{D}-1)}, \\
& R e_{T}=10,000 \times 10^{0.7(\mathrm{P} / \mathrm{D}-1)} .
\end{aligned}
$$

$R e$ is Renoylds number, $L$ for laminar flow, and $T$ for turbulent flow.

Friction factors are provided as follows: $f_{L}=$ $C_{L} / R e$ in the laminar flow, $f_{T}=C_{T} / R e^{0.18}$ in the turbulent flow, and

$$
\begin{aligned}
& f_{t r}=f_{L}(1-\psi)^{1 / 3}+f_{T} \cdot \psi^{1 / 3}, \\
& \text { in the transition flow }
\end{aligned}
$$

where

$$
\psi=\left(\log _{10} R e-\log _{10} R e_{L}\right) /\left(R e_{\mathrm{T}}-\log _{10} R e_{L}\right) .(8 . \mathrm{b})
$$

There are three types of the channels in fuel pin bundle depending on geometry as shown in Figure 6 . Geometry factors are given by

$$
C_{L}, C_{T}=a+b_{1}(P / D-1)+b_{2}(P / D-1)^{2}
$$

where $a, b_{1}$ and $b_{2}$ are constants, and $P$ is pitch of heater pin and the constants are given in Table 3 . Cross sectional average friction coefficients $C_{L}$ and $C_{T}$ are obtained by

$$
C_{f b}=D e_{b}\left[\mathrm{i}=1 \sum^{3} S_{\mathrm{i}}\left(D e / D e_{b}\right)^{\mathrm{m} /(2-\mathrm{m})}\left(C_{f i}^{\prime} / \mathrm{D} e_{i}\right)^{1 /(m-1)}\right]^{m-2}(10)
$$

where $S_{i}=N_{i}\left(A_{i} / A_{b}\right), D_{e b}$ is hydraulic diameter in whole bundle, $D_{e i}$ is hydraulic diameter in each subchannel, $m=1.0$ in laminar flow, and $m=0.18$ in turbulent flow.

Pressure loss at three grid spacers shown in Figure 7 is expressed by

$$
\Delta P_{\mathrm{G}}=(\rho / 2) C_{V} \cdot \varepsilon^{2}\left(V_{b}\right)^{2},
$$

where $C_{V}$ is modification coeff. for honeycomb type grid spacer,

$$
\begin{aligned}
\log _{10}\left(C_{V}\right)=3.018-0.8712 . \log _{10}\left(R e_{b}\right) \\
\quad+8.688 \times 10^{-2} \cdot\left(\log _{10}\left(R e_{b}\right)\right)^{2} \\
\varepsilon=\left(A_{S P} / A\right)
\end{aligned}
$$




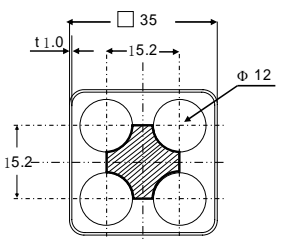

Inner Channel

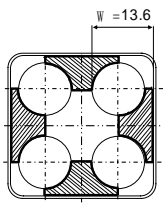

Outer Channel

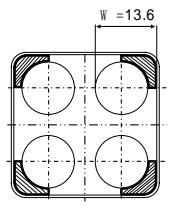

Corner Channel
Figure 6. Inner, outer and corner channels in fuel pin bundle

Table 3. Constants a, b1, b2 at $\mathrm{P} / \mathrm{D} 15.2 / 12=1.27$, $\mathrm{W} / \mathrm{D}=13.6 / 12=1.13$

\begin{tabular}{|l|l|l|l|l|l|l|}
\hline \multirow{2}{*}{ Sub-channels } & \multicolumn{4}{|l|}{ Laminar flow } & \multicolumn{3}{l|}{ Turbulent flow } \\
\cline { 2 - 7 } & $\mathrm{a}$ & $\mathrm{b} 1$ & $\mathrm{~b} 2$ & $\mathrm{a}$ & $\mathrm{b} 1$ & $\mathrm{~b} 2$ \\
\hline Inner channel & 35.6 & 264 & -190 & 0.134 & 0.0906 & -0.0993 \\
\hline Outer channel & 44.4 & 257 & -268 & 0.143 & 0.0420 & -0.0443 \\
\hline Corner channel & 58.8 & 161 & -204 & 0.145 & 0.0268 & -0.0341 \\
\hline
\end{tabular}

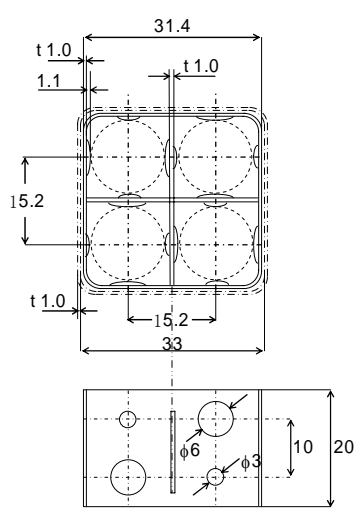

Figure 7. Honeycomb type grid spacer

Frictional pressure losses in the pipes and the other flow resistances given by

$$
\Delta P=[\zeta+\lambda(L / D)](\rho / 2) \cdot V^{2}
$$

\subsection{Drift flux model}

In the absence of the detailed two-phase flow information needed to calculate the buoyancy force, the drift-flux models have been used in the thermalhydraulic analysis. The drift-flux model is one of the most practical and accurate models for two-phase flow calculation. The model takes account of relative motion between phases.

In the previous analytical work ${ }^{9)}$, nondimensional drift-flux model have been used ${ }^{10)}$,

$$
\alpha=j_{w}{ }^{+} /\left[C_{0}\left(j_{w}{ }^{+}+j_{p}{ }^{+}\right)+V_{w j}{ }^{+}\right] \text {. }
$$

The void fraction $(\alpha)$ is expressed as a function of the liquid and gas non-dimensional superficial velocities $j_{p}{ }^{+}$and $j_{w}{ }^{+}$, respectively, a phase distribution parameter $C_{0}$ and the non-dimensional drift velocity between the phases $V_{w j}{ }^{+}$. defined by

Non-dimensional superficial velocities are

$$
j_{k}^{+}=j_{k} /\left((g . \sigma . \Delta \rho) / \rho_{p}^{2}\right)^{0.25}, k=w, p
$$

for the higher viscosity,

$$
\begin{aligned}
& V_{w j}{ }^{+}=0.92\left(\rho_{w} / \rho_{p}\right)^{-0.157}, \\
& C_{0}=1.2-0.2 \sqrt{ }\left(\rho_{w} / \rho_{p}\right) .
\end{aligned}
$$

In the one-dimensional drift flux model used in the present analysis, the void fraction is expressed by the following equation ${ }^{11)}$ :

$$
\alpha=j_{w} /\left[C_{0}\left(j_{w}+j_{p}\right)+V_{w j}\right] .
$$

The liquid and gas superficial velocities $j_{p}$ and $j_{w}$, are defined by

$$
\begin{aligned}
& j_{w}=G_{w} /\left(\rho_{w} A\right), \\
& j_{p}=G_{L} /\left(\rho_{p} A\right),
\end{aligned}
$$

where $G_{w}$ is the steam-water flow rate obtained from experimental data, $G_{L}$ is the unknown $\mathrm{Pb}-\mathrm{Bi}$ flow rate obtained from the calculation, and $A$ is the chimney cross-sectional area. The drift velocity, $V_{w j}$ expressed as follows:

$$
\left.V_{w j}=2.0\left[(g . \sigma . \Delta \rho) / \rho_{\mathrm{p}}^{2}\right)\right]^{0.25} .
$$

The distribution parameter is given by:

$$
C_{0}=1.1
$$

Measured $\mathrm{Pb}-\mathrm{Bi}$ temperature in the $\mathrm{Pb}-\mathrm{Bi}$ flow loop, sub-cooled water temperature, system pressure and heater pin power presented in Table 4 were used for the estimate of $\mathrm{Pb}-\mathrm{Bi}$ physical properties in the above equations.

Table 4. Experiment data

\begin{tabular}{|l|c|c|c|}
\hline & $1^{\text {st }}$ Test & $2^{\text {nd }}$ Test & $3^{\text {rd }}$ test \\
\hline Pressure (MPa) & $<1.0$ & $0.05-6.8$ & 5 \\
\hline Pb-Bi Temp. at inlet ( C) & 290 & $285-400$ & 280 \\
\hline Water inject. Temp. ( C) & 219 & $165-230$ & 210 \\
\hline Heater Power (kW) & $34-50$ & $16-34$ & $41-103$ \\
\hline
\end{tabular}

The distribution parameter and the drift velocity between the phases are computed by fitting the calculated $\mathrm{Pb}-\mathrm{Bi}$ flow rate to experimental data.

\section{Result and Discussion}

After the fitting with the experimental data, the distribution parameter and the drift velocity was obtained as follow:

$$
\left.\alpha=j_{w} /\left[1.1\left(j_{w}+j_{p}\right)+2.0\left[(g \sigma \Delta \rho) / \rho_{p}^{2}\right]\right]^{0.25}\right] \text { (23) }
$$

Experimental data for $\mathrm{Pb}-\mathrm{Bi}$ flow rate are compared with an analytical result in Figures 8 and 9. The data was taken in three experimental conditions in Table 4. In Figure 8, the analytical result agreed reasonably well with the experimental data. However, in the $1^{\text {st }}$ test the analytical result have a discrepancy with experimental data. This may be attributed to dependency of the $\mathrm{Pb}$-Bi flow rate on system pressure.

It was found in Figure 9 that at the low system pressure in the $1^{\text {st }}$ test the analytical result was lower than the experimental data and at the low and the high pressure in the $2^{\text {nd }}$ test the analytical result was lower than the experimental data and agreed well at the pressure of $2-4 \mathrm{MPa}$. 
The reason is that the pressure losses are higher in analytical calculation rather than in experimental. Table 5 shows the average pressure losses as an analytical result. It is found that at the low system pressure less than $0.22 \mathrm{MPa}$ the pressure losses in the chimney is higher than in the heater bundle, which means many bubble are produced in the chimney. Calculated void fraction shows in Figure 10. It is found that the calculated void fraction is high in the low system pressure.

Table 5. Average pressure losses (MPa)

\begin{tabular}{|l|c|c|c|}
\hline & Bundle & Chimney & Down-comer \\
\hline $1^{\text {st }}$ Test & 0.110662 & 0.026908 & 0.050574 \\
\hline $2^{\text {nd }}$ Test & & & \\
\hline $\mathrm{P}<0.22 \mathrm{Mpa}$ & 0.082307 & 0.112858 & 0.037502 \\
\hline $1.0<\mathrm{P}<2.0 \mathrm{MPa}$ & 0.10482 & 0.019533 & 0.047955 \\
\hline $\mathrm{P}>2.0 \mathrm{MPa}$ & 0.080046 & 0.009425 & 0.036487 \\
\hline $3^{\text {rd }}$ Test & 0.069804 & 0.007018 & 0.03159 \\
\hline
\end{tabular}

Comparison of experimental result for $\mathrm{Pb}-\mathrm{Bi}$ flow rate with analysis is shown in Figure 11. The author also compared with a previous analytical work using non-dimensional drift-flux model given by

$$
\begin{aligned}
& \alpha=j_{w}{ }^{+} /\left\{\left[1.2-0.2 \sqrt{ }\left(\rho_{w} / \rho_{p}\right)\right]\left(j_{w}{ }^{+}+j_{p}{ }^{+}\right)\right. \\
& \left.+0.92\left(\rho_{w} / \rho_{p}\right)^{-0.157}\right\}
\end{aligned}
$$

It is found that the deviation of calculation for both models is also less than $20 \%$. It is found that the $\mathrm{Pb}-\mathrm{Bi}$ flow rate obtained from Eq. (24) is slightly lower than that from Eq. (23).

This error can be reduced if an empirical correlation for the void fraction is obtained experimentally to determine the drift velocity and the phase's distribution parameter.

\section{Conclusion}

Boiling two-phase characteristic of $\mathrm{Pb}-\mathrm{Bi}$ water direct contact has been investigated experimentally and analytically, which contribute the analyses of balance condition between pressure losses and the buoyancy forces in the flow channel. The measured $\mathrm{Pb}-\mathrm{Bi}$ flow rate has been evaluated using the drift-flux model. It was found that pressure the calculated flow rate was much lower than experimental data at low system and agreed well with experimental data at pressure range of $2-4 \mathrm{MPa}$. If the effect of surface tension is taken in to account for the drift velocity, the calculated $\mathrm{Pb}-\mathrm{Bi}$ flow rate agreed better with the experimental data.

The deviation between the experimental data and the calculation result is less than $20 \%$.

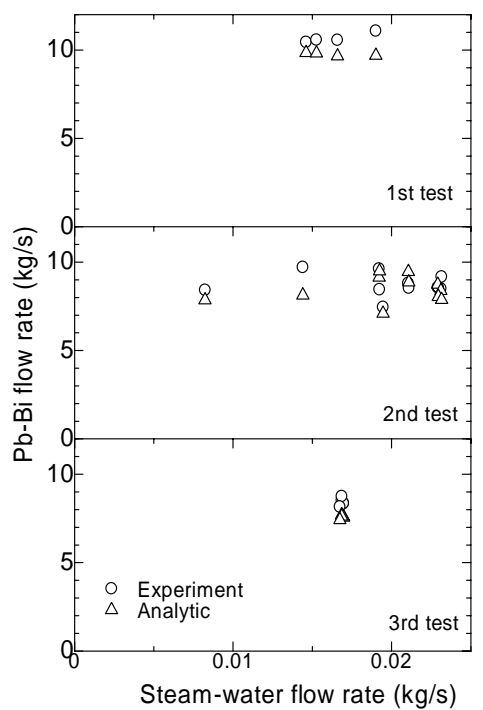

Figure $8 . \mathrm{Pb}-\mathrm{Bi}$ flow rate vs. water-steam flow rate

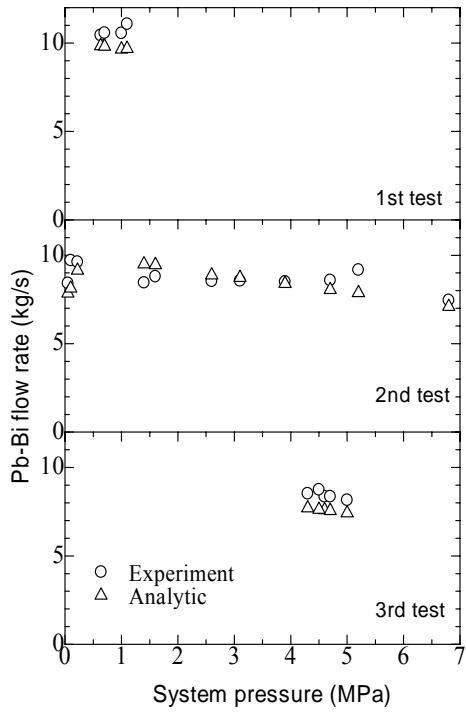

Figure 9. $\mathrm{Pb}-\mathrm{Bi}$ flow rate vs. system pressure

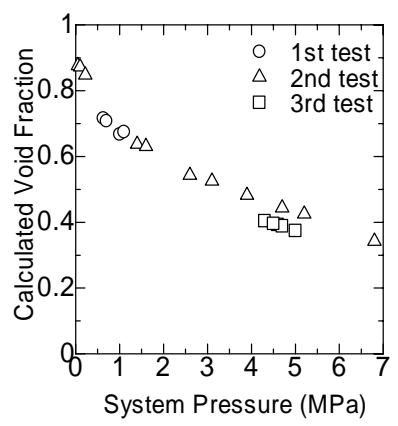

Figure 10. Calculated void fraction vs. System Pressure 


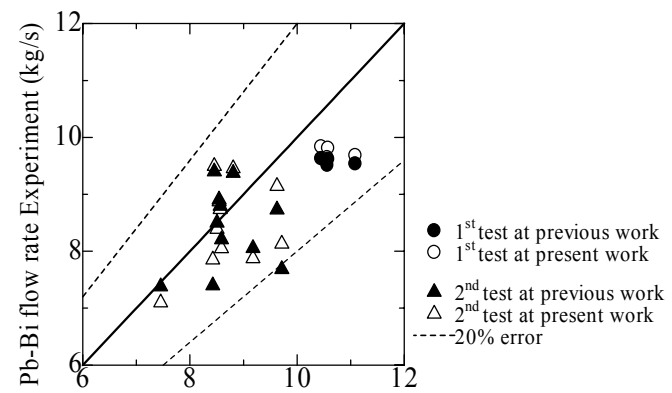

$\mathrm{Pb}-\mathrm{Bi}$ flow rate Experiment $(\mathrm{kg} / \mathrm{s})$

Figure 11. $\mathrm{Pb}-\mathrm{Bi}$ flow rate experiment vs. analysis

\section{References}

1. S. Uchida et al., Conceptual and Safety Design of $\mathrm{Pb}-\mathrm{Bi}$ Cooled Direct Contact Boiling Water Fast Reactor (PBWFR), Proc. of ICAPP '05, Seoul, Korea, May 15-19, 2005, Paper 5172.

2. M. Takahashi et al., Experimental Simulation of Steam Lift Pump and Steam Generation for $\mathrm{Pb}-\mathrm{Bi}$ Cooled Direct Contact Boiling Water Fast Reactor, Proceedings of 2005 International Congress on Advances in Nuclear Power Plants (ICAPP '05), Seoul, Korea, May 15-19, 2005, Paper 5164.

3. M. Takahashi et al., Pb-Bi-Cooled Direct Contact Boiling Water Small Reactor, Progress in Nuclear Energy, 47(1-4), 190-201, 2005.
4. M. Takahashi et al., Study on Pb-Bi Natural Circulation Phenomena, Progress in Nuclear Energy; 47(1-4), 553-560, 2005a.

5. M. Takahashi et al., Study on Pb-Bi-Water Direct Contact Boiling Two-Phase Flow and Heat Transfer, Progress in Nuclear Energy; 47(1-4), 569-576, 2005 b.

6. T. Kashihara, M. Saito and A. Nezu, Gas-liquid Slip Ratio in High Density Liquid-metal TwoPhase Natural Circulation, Proc. $8^{\text {th }}$ Int. Conf. on Nuclear Eng., ICONE-8, Baltimore, MD USA, April 2-6, (2000).

7. T. Hibiki et al, Study on Flow Characteristics in Gas-Molten Metal Mixture Pool, Nuclear Engineering and Design, 196, 233-245, 2000.

8. K. Mikityuk, P. Coddington and R. Chawla, Development of a Drift-flux Model for Heavy Liquid Metal/Gas Flow, J Nucl Sci Technol. 42 (7), 600-607, 2005.

9. Novitrian and M. Takahashi, Analytical Study of $\mathrm{Pb}$-Bi-Water Direct Contact Boiling Two-Phase Flow, Proc. $14^{\text {th }}$ Int. Conf. on Nuclear Eng., ICONE-14, Florida USA, July 17-20, 2006, paper 89436.

10. T. Hibiki, M. Ishii, One-dimensional drift-flux model for two-phase flow in a large diameter pipe, Int. Journal of Heat and Mass Transfer 46, 1773-1790, 2003.

11. M. Ishii, One-dimensional drift-flux model and constitutive equations for relative motion between phases in various flow regimes, Argonne National Laboratory Report, ANL-77-47, 1977. 